\title{
Knowledge Sharing Platforms: An Empirical Study of the Factors Affecting Continued Use Intention
}

\author{
Shichao Pang ${ }^{1}$, Peng Bao ${ }^{1}\left[\right.$, Wenyuan Hao ${ }^{2}$, Jaewoong Kim ${ }^{2}$ and Wei Gu ${ }^{1, *}$ (I) \\ 1 Electronic Commerce, Kongju National University, Kongju 32588, Korea; pangshichao@naver.com (S.P.); \\ baopeng0805@naver.com (P.B.) \\ 2 Computer Science \& Engineering, Kongju National University, Cheonan 31080, Korea; \\ mainfunction@yeah.net (W.H.); jykim@kongju.ac.kr (J.K.) \\ * Correspondence: earily@naver.com; Tel.: +86-153-1804-0320
}

Received: 31 January 2020; Accepted: 11 March 2020; Published: 17 March 2020

\begin{abstract}
Under the background of the constant development of sharing economy and constant upgrade of Internet technologies, various knowledge sharing platforms have emerged in recent years. As a new form for sharing economy, knowledge sharing platforms have made great strides, thus, providing new channels of knowledge acquisition, knowledge sharing and individual knowledge storage for users. Nevertheless, knowledge sharing platforms are still faced with problems, such as uneven product quality (Content quality) and poor user experience. Therefore, how to maintain consumers' continued use intention without impairing consumer satisfaction has obviously become an issue of great concern on the development path of knowledge sharing platforms. Based on the expectation confirmation theory (ECT) and information system (IS) success model, and integrating major characteristics of knowledge sharing platforms, the conceptual models and hypotheses influencing consumers' continued use intention of knowledge sharing platforms are built to study primary factors affecting consumers' continued use intention. Through online and offline questionnaires, 428 copies were collected online, and 150 copies were collected offline, with a total of 578 copies recovered. We deleted some questionnaires with untrue and contradictory answers, because these interviewees might not have carefully read. A questionnaire is conducted with 512 valid copies collected from respondents. At the same time, the structural equation model (SEM) is used to verify and analyze hypotheses. Results show that various variables have a direct or indirect influence on consumers' continued our intention. Meanwhile, it is observed that perceived usefulness and satisfaction degree have a significant influence on continued use intention of knowledge sharing platforms. The higher the satisfaction degree is, the more likely the consumers will continue using knowledge sharing platforms. The expectation confirmation degree exerts an indirect influence on consumers' continued use intention of knowledge sharing platforms via perceived usefulness. The IS success model can also significantly influence consumers' satisfaction degree of knowledge sharing platforms. Additionally, perceived usefulness is observed to have the strongest influence on consumers' continued use intention of knowledge sharing platforms. According to the above research findings, knowledge sharing platforms should strengthen their content quality control, ensure the consistency between service quality and payment, and improve the platform quality. To sum up, this research can provide theoretical bases for sustainable development and follow-up research of the knowledge sharing platform industry.
\end{abstract}

Keywords: knowledge sharing platform; IS success model; expectation confirmation; perceived usefulness; satisfaction; continued use intention 


\section{Introduction}

With the continuous development of information technology, knowledge sharing platforms (KSPs) have ushered in prosperity in recent years and attracted the widespread attention of consumers. KSPs are online communities where users can share, sell, and buy knowledge, as exemplified by Chinese Zhihu, iGetGet, Fenda, and Ximalaya FM, as well as Foreign Skillshare and Udemy. The content on KSPs were free at the beginning; most of the income depends on advertising. However, with the constantly emerging of the knowledge platforms, and the difficulty of the screening of information, increasing the quality of the knowledge may not be able to secure. The users must spend more time and energy, getting valuable and useful free knowledge [1,2]. Therefore, by paying to obtain high quality knowledge will also increase. In order to attract knowledge seekers and producers, in recent years, some of the knowledge sharing platforms to provide paid services as the breakthrough point, allowing knowledge contributors (the seller) and platforms to obtain specific knowledge demanders consulting fees (the buyer). This mode can bring knowledge producers, demanders, and platform interests, respectively. AS for demand of knowledge, they can benefit from the knowledge sharing platforms they need, to a certain extent, improve the efficiency of the users' information screening [3,4]. For knowledge producers, they can obtain corresponding economic returns and pass on their successful methods and experience [5]. For the platform, they get a stable income through commissions, membership fees, advertising and value-added services, etc. [6]. According to the China Sharing Economy Development Report, 2019, released by the Sharing Economy Research Center of State Information Center of China, the market turnover of the knowledge and skills sector in 2018 was approximately 46.4 billion yuan (US $\$ 6.5$ billion), a year-on-year increase of $70.3 \%$, with the number of users reaching up to about 400 million [7].

However, what comes with the continuous emergence of KSPs is their declined quality of knowledge, spoiled word of mouth, lack of content evaluation systems, poor copyright protection, and other issues. For example, the quality of the questions raised by users in the Q\&A community and the answers obtained seem to have been diluted [8]. Accordingly, the visits to KSPs have witnessed a sharp decline [9]. According to a research report released by Penguin Think Tank, only $38 \%$ of users in mainland China are satisfied with KSPs and would continue to use them, $49.7 \%$ have a medium degree of satisfaction, and $12.3 \%$ are dissatisfied. Users have revealed gradually weakened enthusiasm for paying for knowledge, and instead, they begin to rationally examine knowledge consumption. Although knowledge sharing still shows an upward momentum in economic benefits, users' willingness to use KSPs is dropping [10]. Additionally, the surging number of KSPs provides users with more options, so that users are only willing to pay for high-quality, practical knowledge. Therefore, in order to better retain existing users and attract new ones, this study, from the perspective of KSPs, aims to explore how to improve user satisfaction and enhance their willingness for continuous use, to promote the sustainable development of the knowledge sharing industry [5,11].

Although sustainability has been proved playing a key role in the decision-making process of the sharing economy [12-14], current studies give no adequate consideration over the influence of KSPs' content quality on users' willingness for continuous use. Besides, knowledge is of intangibility, not matter for its professionalism, diversity, or accuracy [15], while high-quality information is usually the main driving force for users to use free learning systems or knowledge search engines [16-21]. Compared to other sharing fields, the users in knowledge sharing field have their own characteristics in terms of consumption concepts and behaviors. In such a context, according to the characteristics of KSPs, this study designs a research model by integrating the D\&M IS Success Model and the expectation confirmation theory. The purpose of this study is to explore the main factors influencing consumers' satisfaction with knowledge sharing platforms. First of all the D\&M IS Success Model is used to explore the impact of KSPs' quality on user satisfaction. Then, in combination with KSPs' quality and expectation confirmation theory, the factors affecting users' willingness for continuous use of the KSPs are analyzed. The findings of this study are expected to fill the research gap on KSPs and provide theoretical support for the sustainable development of the knowledge sharing platform industry. 
The remaining parts of this study are structured as below. Section 2 reviews the relevant theoretical background, thus, laying a theoretical basis for the building of the conceptual model in this thesis. Section 3 describes the model built in Section 2 and puts forward hypotheses. Section 4 presents the research methods and verifies the hypotheses above, and Section 5 draws conclusions and inspirations from the above empirical analyses.

\section{Theoretical Review}

\subsection{Knowledge Sharing Platform}

The term "knowledge sharing" has a long history. Believe that knowledge sharing is a process of communication and interaction between the owner of knowledge and the receiver, with knowledge as the core, to improve the utilization value of knowledge [22]. Regards knowledge as an economic resource that can be traded, and knowledge owners can use its usefulness and rarity to trade in the knowledge market, while the transaction of knowledge sharing is the process of knowledge trading [23,24]. With the mature Internet information technology, information technology has become an important tool for knowledge sharing. Some scholars think that knowledge sharing in a very great degree is determined by information technology and its use, emphasize the important role of knowledge in knowledge sharing. Knowledge sharing platform as the user interaction and information sharing network of public space, by the repeated communication, knowledge sharing, and improve the utilization value of knowledge [25-27]. The study points out that the exchange of information and knowledge is becoming easier because of the Internet [28,29].

Knowledge payment platform refers to that knowledge providers provide knowledge and information to people in need for a fee, which has typical characteristics of e-commerce (i.e., sales and purchase) [30]. Divided knowledge payment into paid questions and answers, paid courses and columns, live social broadcasting and other types. Moreover, some researchers have explained the reasons why users seek paid knowledge and adopt online knowledge [15,17]. In particular, why users use the knowledge payment platform to acquire knowledge [31]. High-quality information motivates users to use knowledge communities or learning systems because they are useful and can improve individual performance. Because they are useful, they can improve individual performance [29,32,33], which proves that the professionalism, diversity and accuracy of knowledge, as well as the convenience, timeliness and interactivity of search, improve users' willingness to search for knowledge and use the knowledge payment platform [32].

Knowledge sharing platform is mainly through information dissemination at the transmission level, marketing promotion at the market level and service and feedback at the users' level. The service provides content producers feedback as the core of value to provide user needs. Based on this, the platform continuously introduces knowledge products and services to meet the basic needs of users [34]. At the same time, the feedback of users can best reflect the publicity effect of the market, stimulate the market level to continuously increase the promotion of the platform's "all-round knowledge service", and tap potential users; On the other hand, users' feedback directly acts on information transmission at the transmission level, guiding the platform to establish a high level of connection with users' psychology and behavior through more innovative communication methods [35].

Information dissemination at the communication level, on the one hand, sets up a new knowledge scene for the knowledge sharing platform spire to promote the collaborative production of knowledge, and on the other hand, receives high-quality content at the content level and transmits it to users in the knowledge sharing environment. Furthermore, information can be formed through the platform of high-speed, wide dissemination, marketing promotion to assist [36]. Moreover, the platform word-of-mouth formed by marketing can play a role in knowledge dissemination, expanding the dissemination effect, and lay a foundation for knowledge realization. Therefore, these three levels interact with each other and at the same time, interact with the core elements of the operation model. In the end, knowledge information is transmitted through payment, which is oriented to profit [37-39]. 
As a byproduct of the Internet development, the knowledge sharing platform is in itself a network space for basic communication and sharing between knowledge providers and receivers. The knowledge sharing platform relies on the Internet to share the fragmented knowledge with users in need of certain knowledge or information and having the time to acquire such knowledge or information.

According to different consumer needs (such as knowledge of the law, finance, business, psychology, medical care and health, science and technology, sports, art, tourism and Internet), knowledge sharing platforms can be divided into several categories. By collecting user characteristics and habits, knowledge sharing platforms can provide high-quality content and services for consumers to satisfy consumer demands [36].

In spite of the huge potential of knowledge sharing platforms, the growing content quantity of knowledge sharing platforms might bring about a series of problems, including poor content quality, content homogenization and lack of copyright protection [40]. This necessitates further research of factors influencing consumers' continued use intention. Therefore, in advocating consumers' use of knowledge sharing platforms, researchers should study the psychological and behavioral perception of consumers before and after their use of knowledge sharing platforms to effectively help the knowledge sharing industry improve the content quality, service quality and development strategies, and resolve users' core knowledge demands, thus, finally realizing sustainable development.

\subsection{IS Success Model}

DeLone and McLean summarize IS empirical research of the validity of Management Information Service (MIS) in the past, and puts forward the IS success model [41]. According to the D\&M's IS success model, dependent variables of MIS research are divided into six categories, including system quality, information quality, system use, user satisfaction, personal influence and organizational influence. At the same time, the temporal relationship among these dependent variables is put forward. Among them, system quality and information quality can affect system use, which will further influence user satisfaction, personal performance and final organizational performance [42]. In a bid to ensure D\&M IS success model to cope with the academic assessment needs of various system role changes, DeLone and McLean developed an improved D\&M IS success model with service quality introduced, merging personal influence and organizational influence into net earnings, regarding user satisfaction as an important index to measure IS success, and holding that information quality, system quality and service quality can jointly influence user satisfaction and willingness to use [43].

So far, the IS success model has found wide applications in examining users' use of various information systems. Chen and Cheng use the IS success model to verify consumers' willingness to go shopping online [44]. Gao and Bai employ the IS success model to explain users' continued use intention of mobile social network services [45].

Though the practicability and feasibility of the IS success model have been vigorously substantiated by extensive research into information systems, seldom has it been used to inspect the continued use behavior of knowledge sharing platforms. Therefore, to apply the IS success model to research into the knowledge sharing platform can make up the current research gap. Since the knowledge platform is one kind of information systems, it is feasible to adopt IS success model as a theoretical basis of the research model in this paper.

\subsection{Expectation Confirmation Model}

Expectation-confirmation theory (ECT) was developed in 1980 [46], which is a basic theory used to study consumer satisfaction. By definition, ECT is to compare the consumer expectation before buying a certain product or service and the perceived performance after buying for confirmation of whether the consumer is satisfied with the product or service. The consumer satisfaction, thus, obtained can provide a reference for repurchase intention. In 2001, Bhattacherjeet developed the Expectation-confirmation model (ECM) based on ECT to study user persistent behavior in the field of information systems [47]. 
Perceived usefulness is introduced to the model, which can directly influence user satisfaction and continued use intention. According to the information system, ECM, expectation confirmation is to compare the user expectation before using the information system and the cognition after using. The perceived usefulness refers to the user's perception of the actual performance of the information system after using it. The expectation confirmation degree can influence the perceived usefulness and satisfaction, and further influence the continued use intention. The higher the expectation confirmation degree is, the more useful the system is perceived by the user, the more satisfied the user is with the system, and the stronger the user's continued to use information is [48]. Currently, many researchers have verified the validity of the ECM in various information system products and services [49-53].

The representativeness of ECM has been substantiated more than once [45,54,55]. According to differences of research objects, prior scholars have built different research models on the basis of $\mathrm{ECM}$, and combining the technology acceptance theory, IS success model, e-commerce trust theory, value perception theory and self-efficacy theory to study the user's continued use intention of different information systems, including mobile apps [56], online learning platforms [52,57,58], or web-based service systems [59-61].

\subsection{Continued Use Intention}

As an independent variable, continued use intention can reflect the intensity of the user's willingness to use the information system again. Some scholars regard continued use intention as the behavioral performance following the first use [62]. Continued use intention is more important than initial acceptance $[47,59]$. The continued use intention theory studies the information use process through the assessment, strengthening and feedback of the interaction process between users and products, information and services. Once consumers develop the intention to use the platform, it is of vital importance for the knowledge sharing platform to maintain user involvement.

\subsection{Integration Between IS Success Model and ECM}

ECM is the theory used most widely to examine consumer satisfaction [46]. Research has suggested the feasibility of combining the IS success model and ECM for the examination of research issues. However, a majority of scholars think that information quality, service quality and system quality can directly influence the expectation confirmation degree and perceived usefulness, thus, affecting user satisfaction and continued use intention [63-65]. Some scholars have combined the ECM and IS success model to verify the positive influence of information quality, system quality and service quality on user satisfaction $[63,66,67]$. According to prior research findings (such as research into integrated trust [68,69], integrated self-efficacy [70], social cognitive theories [42], integrated perceived value [71], and subjective norm [72] all regards system quality, service quality and information quality as factors directly influencing consumer satisfaction. Compared with the use of the IS success model alone, the integrated ECM and IS success model can more satisfactorily explain key factors affecting consumer satisfaction and continued use intention. Therefore, this paper integrates the ECM and IS success model, and builds the conceptual model for this research according to the corresponding characteristics of the platform's service quality, information quality and system quality (such as the information system functions, knowledge platform's information reliability and consumer Q\&A service quality), and influence of perceived usefulness and expectation confirmation degree on user satisfaction and continued use intention.

\section{Research Model and Hypotheses}

\subsection{Research Model}

This paper integrates the ECM and IS success model, and builds the conceptual ECM research model for this research according to the corresponding characteristics of the platform's service quality, information quality and system quality (such as the information system functions, knowledge 
platform's information reliability and consumer Q \& A service quality), and influence of perceived usefulness and expectation confirmation degree on user satisfaction and continued use intention. As shown in Figure 1.

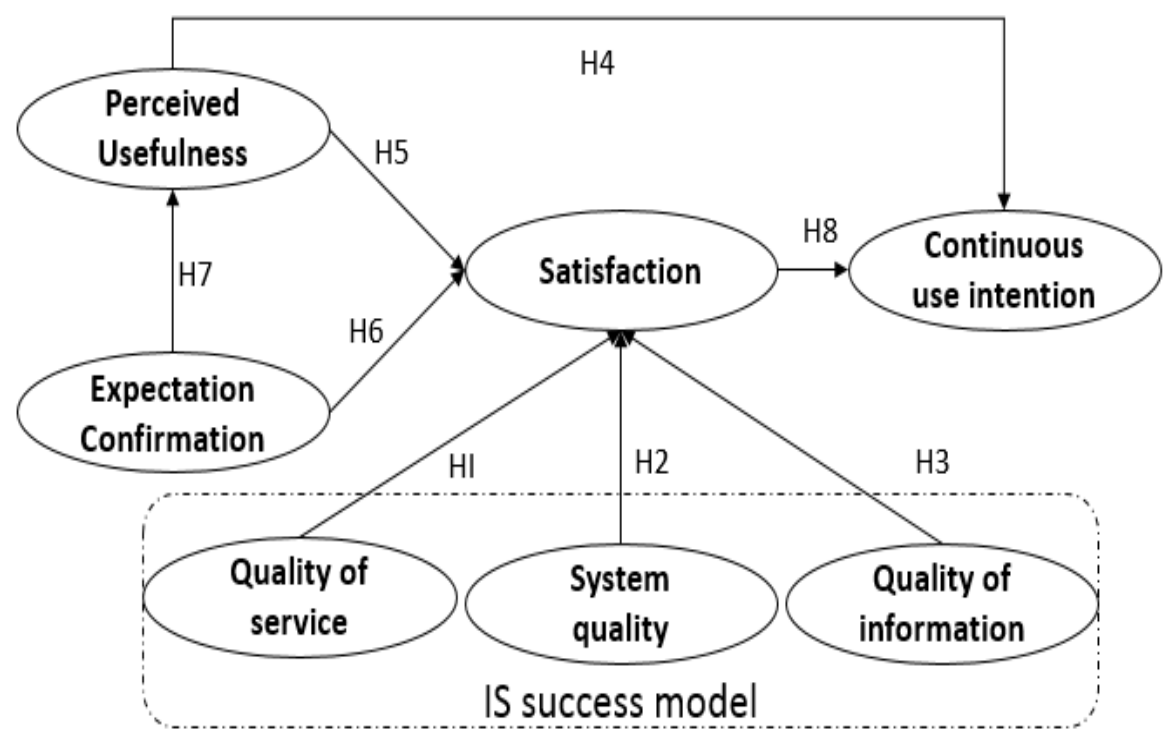

Figure 1. Research model.

\subsection{Research Hypotheses}

\subsubsection{Hypotheses of Service Quality, System Quality, Information Quality and User Satisfaction}

User satisfaction is one of the key factors assessing platform use, so it has found wide application in the IS success research $[73,74]$ by defining user satisfaction with platform functions, content quality, and system response speed as a measure of system usefulness. Research has shown a significant correlation between information quality and user satisfaction [75], a significantly positive influence of service quality on satisfaction with online learning [76-79], and information quality as a key dimension to assess user satisfaction and whether the electronic learning system can be successful $[79,80]$. Information quality is usually regarded as a critical factor affecting user satisfaction [77,81-83]. Therefore, the quality of the information provided by the system can influence user satisfaction and indirectly influence the user's continued use intention. Research findings also indicate that system quality can directly and positively influence user satisfaction, and indirectly influence the user's system use [80]. This suggests that learning functions, discussion communities, auxiliary learning tools and other functions of the mobile learning system might, to a large extent, improve the user satisfaction and user's use of online systems. Meanwhile, there is a positive correlation between system quality and user satisfaction [19,83]. The IS success model can influence the user's recognition of the system [84]. The IS success model can reveal the correlation of system quality, service quality, and information quality with user satisfaction and use intention [85], and the feasibility of applying the IS success model to research into the electronic learning system is substantiated, thus, providing a platform for mutual exchange (knowledge sharing) between learners and knowledge providers. In this research, service quality, system quality, and information quality are believed to have a positive influence on consumer satisfaction. Based on the above discussions, the following hypotheses are made:

Hypothesis 1 (H1). Service quality can positively influence consumer satisfaction with the knowledge sharing platform.

Hypothesis 2 (H2). System quality can positively influence consumer satisfaction with the knowledge sharing platform. 
Hypothesis 3 (H3). Information quality can positively influence consumer satisfaction with the knowledge sharing platform.

\subsubsection{Hypotheses of the ECM}

When the actual performance of the information system lives up to consumer expectation, the consumer will perceive its usefulness and obtain a high degree of satisfaction $[39,43,86]$. According to the ECM, perceived usefulness can influence the continued use intention of the information system [32]. According to the literature [54,61], the direct and positive influence of perceived usefulness on user satisfaction and continued use intention is pointed out. Similarly, when the consumer perceives the usefulness of the platform system, they tend to use the platform continuously. The continued use intention is decided by personal satisfaction with the information system. More than one research finding has suggested the feasibility of using the ECM to explore the continued use intention. Zheng et al. [87] examine the influence of user satisfaction on the continued use intention in the virtual community. When the user obtains a high degree of satisfaction with the intelligent watch, the user will show a stronger intention to continuously use the intelligent watch [61]. Additionally, research into the electronic learning system reveals that the perceived usefulness and user satisfaction with the system can significantly influence the user's continued use intention [84]. In this paper, the knowledge sharing platform can be regarded as the information system. When the user is satisfied with the knowledge sharing platform, the user will demonstrate a stronger intention to use the knowledge sharing platform. Based on the above discussions, this research makes the following hypotheses:

Hypothesis 4 (H4). Perceived usefulness can positively influence consumer's continued use intention of the knowledge sharing platform.

Hypothesis 5 (H5). Perceived usefulness can positively influence consumer's satisfaction with the knowledge sharing platform.

Hypothesis 6 (H6). Expectation confirmation degree can positively influence consumer's satisfaction with the knowledge sharing platform.

Hypothesis 7 (H7). Expectation confirmation degree can positively influence consumer's perceived usefulness of the knowledge sharing platform.

Hypothesis 8 (H8). User satisfaction can positively influence consumer's continued use intention of the knowledge sharing platform.

\section{Verification of Hypotheses}

\subsection{Questionnaire Design}

The following questionnaire is designed by referring to mature scales studying information system use behaviors at home and abroad. At the same time, research findings concerning information system use behaviors at home and abroad are examined to make modifications of the scale. Every research variable adopts at least four measurement indexes. The questionnaire is designed on the basis of the five-point Likert scale, with " 1 " indicating "strongly disagree" and " 5 ' indicating "strongly agree". In order to ensure the validity of the questionnaires filled by respondents, the designed questionnaire is sent to three experts in this field for suggestions. The author modifies the questionnaire according to experts' suggestions, and carries out a small-scale questionnaire among Chinese students studying in South Korea. In light of the survey results, the final questionnaire is designed. The measurement indexes and references adopted by this questionnaire are shown in Appendix A. 


\subsection{Data Collection and Sample Statistics}

The questionnaire mainly adopts Chinese consumers with the user experience of knowledge sharing platforms as research objects. The questionnaire was delivered and collected online from 2 September 2019 to 12 October 2019. Through online and offline questionnaires, 428 copies were collected online, and 150 copies were collected offline, with a total of 578 copies recovered. We deleted some questionnaires with untrue and contradictory answers, because these interviewees might not have carefully read. In total, 512 copies were collected. Through descriptive statistical analysis of the 512 copies using IBM SPSS Statistics 24.0 and IBM SPSS AMOS 24.0, results show that $57.8 \%$ of knowledge sharing platform users are males, and $42.4 \%$ are females. Age of the users concentrates on the range from 21 years old to 40 years old, accounting for $74 \%$ of the total. Their educational degree is mainly the junior college and the undergraduate, accounting for $66.6 \%$ of the total. The users earning a monthly salary of around 3,100 RMB to 5,000 RMB are in the majority. Most users are students and company staff. See Table 1. Below:

Table 1. Sample characteristics.

\begin{tabular}{|c|c|c|c|}
\hline Variables & Items & Frequency & Percentage \\
\hline \multirow{2}{*}{ Gender } & Male & 296 & $57.8 \%$ \\
\hline & Female & 216 & $42.2 \%$ \\
\hline \multirow{5}{*}{ Age } & Below 20 & 71 & $13.9 \%$ \\
\hline & $21 \sim 30$ & 211 & $41.2 \%$ \\
\hline & $31 \sim 40$ & 168 & $32.8 \%$ \\
\hline & $41 \sim 50$ & 46 & $9 \%$ \\
\hline & Above 50 & 16 & $3.1 \%$ \\
\hline \multirow{5}{*}{ Academic Degree } & Middle school or below & 43 & $8.4 \%$ \\
\hline & $\begin{array}{l}\text { Senior high school (including higher } \\
\text { vocational education) }\end{array}$ & 62 & $12.1 \%$ \\
\hline & Junior college & 142 & $27.7 \%$ \\
\hline & Undergraduate & 199 & $38.9 \%$ \\
\hline & Postgraduate or above & 66 & $12.9 \%$ \\
\hline \multirow{5}{*}{ Profession } & Student & 201 & $39.3 \%$ \\
\hline & Freelancer & 98 & $19.1 \%$ \\
\hline & Public servant & 78 & $15.2 \%$ \\
\hline & Company employee & 109 & $21.3 \%$ \\
\hline & Others & 26 & $5.1 \%$ \\
\hline \multirow{5}{*}{ Monthly Income (RMB) } & Lower than 3000 & 76 & $14.8 \%$ \\
\hline & $3100 \sim 5000$ & 198 & $38.7 \%$ \\
\hline & $5100 \sim 7000$ & 107 & $20.9 \%$ \\
\hline & $7100 \sim 10,000$ & 79 & $15.4 \%$ \\
\hline & Above 10,000 & 52 & $10.2 \%$ \\
\hline
\end{tabular}

\subsection{Reliability and Validity}

In order to verify the reliability and validity of measurement scales, the composite reliability $(\mathrm{CR})$ is used to measure the internal consistency of various measurement items, while the value of Cronbach's Alpha is used to measure the reliability of various factors. When the value of CR and Cronbach's Alpha is both larger than 0.8, the reliability is acceptable [88]. Results show the Cronbach's Alpha value of all latent variables is larger than 0.8 , which is up to the requirement of reliability. In order to verify the validity of variables in this research, the convergence validity and the discriminant validity are adopted. Verification of the convergence validity consists of verification of the composite reliability and the average variation extraction (AVE) to assess the convergent validity of the measurement model. Table 2 shows that the value of CR and Cronbach's Alpha is both larger than 0.8, and the value of AVE is larger than 0.5 , it suggests high reliability of internal consistency and a favorable convergent validity 
of the model [89-94]. The discriminant validity can be measured by whether the AVE square root of latent variables is larger than the correlation coefficient of latent variables. If the former is larger than the latter, it indicates a favorable discriminant validity of the questionnaire [91]. According to Table 3, the AVE square root of the research data is greater than the correlation coefficient of each factor, and the discriminant validity is ensured.

Table 2. Convergent validity and reliability.

\begin{tabular}{|c|c|c|c|c|c|c|}
\hline Construct & Indicators & Factor Loading & SMC & AVE & CR & Cronbach's \\
\hline \multirow{4}{*}{$\begin{array}{l}\text { Service } \\
\text { Quality }\end{array}$} & SEQ1 & 0.836 & 0.699 & \multirow{4}{*}{0.589} & \multirow{4}{*}{0.851} & \multirow{4}{*}{0.850} \\
\hline & SEQ2 & 0.736 & 0.542 & & & \\
\hline & SEQ3 & 0.702 & 0.493 & & & \\
\hline & SEQ4 & 0.790 & 0.624 & & & \\
\hline \multirow{4}{*}{$\begin{array}{l}\text { System } \\
\text { Quality }\end{array}$} & SYQ1 & 0.778 & 0.605 & \multirow{4}{*}{0.592} & \multirow{4}{*}{0.853} & \multirow{4}{*}{0.852} \\
\hline & SYQ2 & 0.836 & 0.699 & & & \\
\hline & SYQ3 & 0.731 & 0.534 & & & \\
\hline & SYQ4 & 0.729 & 0.532 & & & \\
\hline \multirow{4}{*}{$\begin{array}{c}\text { Information } \\
\text { Quality }\end{array}$} & INQ1 & 0.873 & 0.762 & \multirow{4}{*}{0.544} & \multirow{4}{*}{0.825} & \multirow{4}{*}{0.814} \\
\hline & INQ2 & 0.724 & 0.525 & & & \\
\hline & INQ3 & 0.635 & 0.404 & & & \\
\hline & INQ4 & 0.697 & 0.486 & & & \\
\hline \multirow{4}{*}{$\begin{array}{l}\text { Expectation } \\
\text { Confirmation }\end{array}$} & EC1 & 0.720 & 0.519 & \multirow{4}{*}{0.601} & \multirow{4}{*}{0.857} & \multirow{4}{*}{0.856} \\
\hline & EC2 & 0.823 & 0.677 & & & \\
\hline & EC3 & 0.757 & 0.573 & & & \\
\hline & EC4 & 0.796 & 0.633 & & & \\
\hline \multirow{4}{*}{$\begin{array}{l}\text { Perceived } \\
\text { Usefulness }\end{array}$} & PU1 & 0.836 & 0.699 & \multirow{4}{*}{0.679} & \multirow{4}{*}{0.894} & \multirow{4}{*}{0.894} \\
\hline & PU2 & 0.839 & 0.704 & & & \\
\hline & PU3 & 0.789 & 0.622 & & & \\
\hline & PU4 & 0.830 & 0.688 & & & \\
\hline \multirow{4}{*}{ Satisfaction } & SAT1 & 0.678 & 0.459 & \multirow{4}{*}{0.521} & \multirow{4}{*}{0.812} & \multirow{4}{*}{0.811} \\
\hline & SAT2 & 0.669 & 0.447 & & & \\
\hline & SAT3 & 0.757 & 0.574 & & & \\
\hline & SAT4 & 0.777 & 0.604 & & & \\
\hline \multirow{4}{*}{$\begin{array}{l}\text { Continued } \\
\text { Use } \\
\text { Intention }\end{array}$} & CUI1 & 0.749 & 0.721 & \multirow{4}{*}{0.703} & \multirow{4}{*}{0.904} & \multirow{4}{*}{0.903} \\
\hline & CUI2 & 0.872 & 0.761 & & & \\
\hline & CUI3 & 0.827 & 0.683 & & & \\
\hline & CUI4 & 0.804 & 0.647 & & & \\
\hline
\end{tabular}

Note: $\mathrm{CR}=$ composite reliability; $\mathrm{AVE}=$ average variation extraction; $\mathrm{SMC}=$ squared multiple correlation.

Table 3. Discriminant validity analysis.

\begin{tabular}{cccccccc}
\hline Construct & SEQ & SYQ & IQ & EC & PU & SAT & CUI \\
\hline SEQ & $\mathbf{1 . 0 0 0}$ & & & & & & \\
SYQ & 0.336 & $\mathbf{1 . 0 0 0}$ & & & & & \\
IQ & 0.364 & 0.273 & $\mathbf{1 . 0 0 0}$ & & & & \\
EC & 0.152 & 0.172 & 0.210 & $\mathbf{1 . 0 0 0}$ & & & \\
PU & 0.227 & 0.138 & 0.278 & 0.489 & $\mathbf{1 . 0 0 0}$ & & \\
SAT & 0.399 & 0.659 & 0.417 & 0.342 & 0.327 & $\mathbf{1 . 0 0 0}$ & \\
CUI & 0.182 & 0.169 & 0.276 & 0.472 & 0.595 & 0.367 & $\mathbf{1 . 0 0 0}$
\end{tabular}

Note: Diagonals represent the AVE, and the other matrix entries represent the squared factor correlations. PU: Perceived Usefulness EC: Expectation Confirmation. SEQ: Service quality SYQ: System quality. IQ: Information quality. SAT: Satisfaction. CUI: Continuous use intention. 


\subsection{Hypothesis Testing}

This research mainly uses AMOS 24.0 to conduct confirmatory factor analysis of the structural equation model (SEM). In order to ensure the consistency between the data and the research data and hypotheses, the model's degree of fitting should conform to relevant requirements: $\mathrm{x} 2 / \mathrm{df} \leq 3.00$, GFI and AGFI $\geq 0.90$, RMSEA $<0.08$ (reasonable degree of fitting) or $<0.05$ (favorable degree of fitting), NFI, IFI and CFI $>0.90$ [94]. The degree of fitting of the research model is $x 2 / \mathrm{df}=2.079, \mathrm{NFI}=0.911$, $\mathrm{GFI}=0.914, \mathrm{AGFI}=0.896, \mathrm{IFI}=0.952, \mathrm{CFI}=0.952$, and RMSEA $=0.046$. All the above indexes satisfy the standard requirements. Verification results show that the service quality of the user's knowledge sharing platforms $(\beta=9.803)$, system quality $(\beta=2.317)$, and information quality $(\beta=3.662)$ has a significantly positive influence on user satisfaction of the knowledge sharing platform. The user's perceived usefulness of the knowledge sharing platform can significantly and positively influence user satisfaction with the knowledge sharing platform $(\beta=2.228)$ and continued use intention $(\beta=11.459)$. The user's perceived usefulness has the greatest influence on the continued use intention of the knowledge sharing platform. The user's expectation confirmation degree of the knowledge sharing platform can positively influence user satisfaction $(\beta=2.950)$ and perceived usefulness $(\beta=9.741)$. User satisfaction with the knowledge sharing platform can positively influence the user's continued use intention $(\beta=4.444)$. To sum up, all hypotheses made by this research are substantiated, as shown in Table 4 and Figure 2.

Table 4. Results of hypothesis analysis.

\begin{tabular}{ccccccc}
\hline Hypothesis & Path & Estimate & t-Value & S.E. & $p$-Value & Result \\
\hline H1 & SEQ $\rightarrow$ SAT & 0.383 & 9.803 & 0.039 & $* * *$ & Supported \\
H2 & SYQ $\rightarrow$ SAT & 0.087 & 2.317 & 0.037 & 0.021 & Supported \\
H3 & IQ $\rightarrow$ SAT & 0.136 & 3.662 & 0.037 & $* * *$ & Supported \\
H4 & PU $\rightarrow$ CUI & 0.648 & 11.459 & 0.057 & $* * *$ & Supported \\
H5 & PU $\rightarrow$ SAT & 0.078 & 2.228 & 0.035 & 0.026 & Supported \\
H6 & EC $\rightarrow$ SAT & 0.127 & 2.950 & 0.043 & 0.003 & Supported \\
H7 & EC $\rightarrow$ PU & 0.589 & 9.741 & 0.060 & $* * *$ & Supported \\
H8 & SAT $\rightarrow$ CUI & 0.334 & 4.444 & 0.075 & $* * *$ & Supported \\
\hline
\end{tabular}

Note: ${ }^{* * *} p<0.001$. Note: PU: Perceived Usefulness EC: Expectation Confirmation. SEQ: Service quality SYQ: System quality. IQ: Information quality. SAT: Satisfaction. CUI: Continuous use intention.

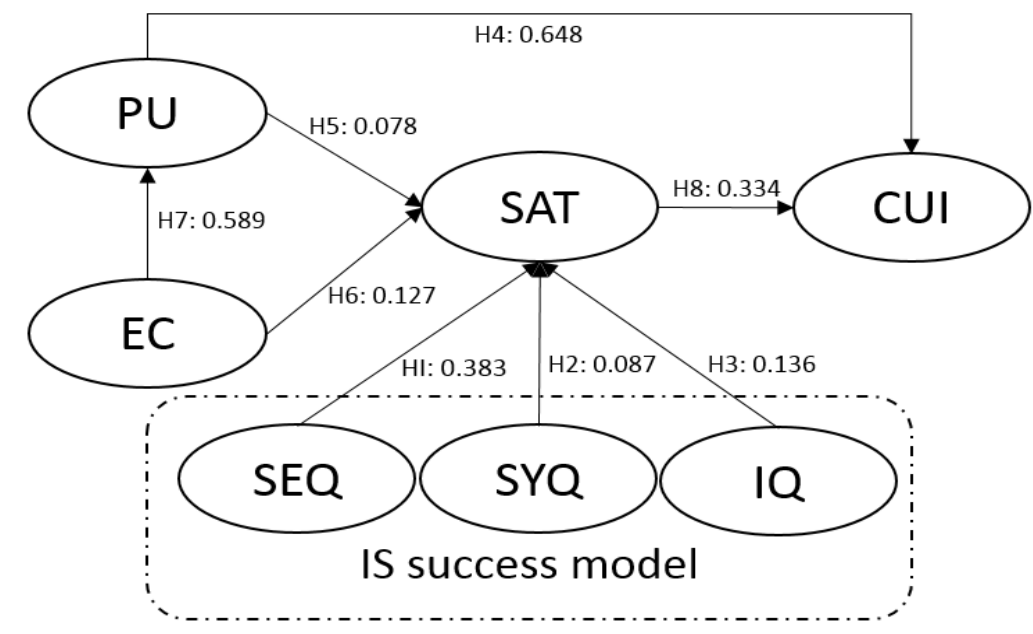

Figure 2. Results of the research model. Note: PU: Perceived Usefulness EC: Expectation Confirmation. SEQ: Service quality SYQ: System quality. IQ: Information quality. SAT: Satisfaction. CUI: Continuous use intention. 


\section{Discussion and Conclusions}

\subsection{Discussion}

In the context where the knowledge sharing platform industry is confronted with increasingly fierce competition and gradually refining market segmentation, how to realize sustainable development and retain users has turned into a tricky challenge facing KSPs. With the ECM-IS integrated model, this study identifies the dominant factors affecting users' willingness for continuous use of KSPs. The integrated model combines multiple explanatory variables, such as perceived usefulness, degree of expectation confirmation, service quality, system quality, information quality, and degree of satisfaction, that are taken as the determinants affecting users' willingness for continuous use.

The verification analysis results of this study suggest that service quality, system quality, and information quality have a positive and significant impact on user satisfaction with KSPs; the path coefficients from service quality, system quality, and information quality are $0.383,0.087$, and 0.136 , respectively, which fully shows that service quality is the top factor to be considered by users when they use KSPs. This finding is consistent with the conclusions of existing studies [76-78]. The services provided by KSPs should be timely, comprehensive and high-quality, to help users solve specific problems encountered during platform use, strengthen their connection with users, and meet user needs. Information quality reflects the professionalism, accuracy, and usefulness of the knowledge provided by KSPs [75,77]. With the continuous increase in the number, the content of knowledge sharing platform tends to be entertainment. The professional level of knowledge producers is uneven, and the copyright protection of knowledge being insufficient. Therefore, knowledge sharing platforms should remove entertaining content, get rid of the tendency of excessive entertainment of part of knowledge content, focus the value of knowledge dissemination on knowledge itself, and enhance the protection of knowledge copyright in a bid to help users reduce perceived uncertainty in terms of technical means and users' consumption intention. System quality reflects KSPs' level in page design, available access speed and so on, so KSP management should take actions to continuously perfect their website system to make sure clear and neat page layouts, efficient retrieval availability, and reliable uninterrupted services. Seen from the perspective of users, a high-quality system helps users get a glimpse of platform strength and raise their trust in the platform, thereby affecting user satisfaction with it. This finding echoes the conclusions of some researchers [19,95]. Therefore, high-quality information, services, and system quality can improve user experience and help increase user satisfaction with KSPs.

Besides, expectation confirmation has a significant impact on consumer satisfaction and perceived usefulness. The path coefficients from expectation confirmation and perceived usefulness to the degree of satisfaction are 0.127 and 0.589 , respectively. In other words, the better KSPs to meet user expectations, the higher the degree of performance perceived by users, and the higher the degree of their satisfaction, thereby strengthening their willingness for continuous use. This finding is consistent with ECM hypotheses and some empirical study conclusions, for example, the degree of confirmation is a key determinant of user satisfaction. Perceived usefulness has a significant positive impact on user satisfaction and willingness for continuous use $[49,96]$, and the path coefficient from perceived usefulness to a willingness for continuous use is 0.648 . This finding is consistent with the conclusions of some researchers [56,65]. This shows that the platform is the same as other platforms, and that perceived usefulness and satisfaction can enhance consumers' willingness to use the platform. Therefore, KSPs should spare no effort to foster users' understanding of their functions and advantages, and take actions to help users more aware of their usefulness, in an attempt to raise users' willingness for continuous use.

In the end, the degree of satisfaction has a significant positive impact on users' willingness to continuously use KSPs. The path coefficient from the degree of satisfaction to a willingness for continuous use is 0.334 , which is consistent with the conclusion of some existing studies $[87,97]$ that the overall user satisfaction degree is one of the key factors in evaluating the use of KSPs [75]. When users are generally satisfied with a KSP, their willingness for continuous use tends to increase. Therefore, 
improving user satisfaction with KSPs is still the main way to increase users' willingness for continuous use. The structural model calculation results show that the structure is of certain practical value, which suggests that the ECM-IS integrated model well explains users' willingness to continuously use KSPs.

\subsection{Conclusions}

This study verifies the causal relationship among the variables by integrating the ECM and IS theories, and its design and findings are of certain academic significance to explore users' willingness to continuously use KSPs and promote the development of the entire knowledge sharing platform industry. Moreover, this study expands the scope of research on knowledge sharing platform industry and promises to lay a solid theoretical foundation for subsequent research.

Theoretically speaking, this study, first of all, further confirms that both ECM and IS theories can be applied to studying users' willingness for continuous use of information systems, including KSPs, and enrich and deepen the theoretical systems of ECM and IS, thereby contributing to the theoretical development of KSPs-related research. Additionally, knowledge sharing has entered the stage of paid knowledge acquisition, so it is of great importance to explore users' willingness to continuously use KSPs. The results of this study show that KSP developers should constantly optimize their service quality and information quality to increase user satisfaction, and thus, uplift users' willingness for continuous use if they want to retain existing users and solicit new ones. This finding provides valuable theoretical references for the knowledge sharing platform industry to screen and create higher-quality content.

Practically speaking, system quality, service quality, and information quality significantly affect user satisfaction with KSPs. In a context where the content of KSPs is of varying quality, users cast doubt over whether the knowledge provided by the platforms can effectively benefit them, which may turn into a major obstacle to users' willingness for continuous use of KSPs. For this reason, in the operation of the knowledge sharing platform, a strict content screening mechanism should be established to prevent the emergence of excessive entertainment and malicious hype of knowledge information, and the protection of intellectual property rights should be enhanced to help consumers reduce the perception of uncertainty. Moreover, good service quality is especially important for users who use the knowledge sharing platform for the first time, which is the prerequisite to win users' recognition and satisfaction. Therefore, the knowledge sharing platform should develop quick and effective users' response mechanism to ensure that it can help users quickly solve the problems encountered in use. We should emphasize the requirements of user platform quality, because users' perceived usefulness and expectations of the platform affect their satisfaction and willingness to continue using the knowledge sharing platform. Therefore, platform developers should pay attention to the actual use of the platform in the design phase, simplify the search process and wait time, to enhance users' experience and users' stickiness, improve user perceived usefulness and expectations, and thereby improve users' satisfaction and willingness to continue using. A high-quality system is in favor of users perceiving the strength of KSPs, thereby improving user satisfaction. Expectation confirmation has a significant positive impact on both users' degree of satisfaction and perceived usefulness of KSPs. Satisfaction is the core of improving user loyalty and willingness for continuous use of KSPs. Hence, in order to improve user loyalty, reduce customer attrition, and maintain their willingness for continuous use, KSPs should focus on enhancing user experience and meeting user expectations, in an attempt to improve user expectation confirmation and perceived usefulness, which in turn boosts user satisfaction and willingness for continuous use.

The research results of this study offer the following revelations for the knowledge sharing platform industry. First of all, KSPs should establish a sound knowledge content review system that regulates content production process and makes sure the accuracy and professionalism of the information provided. Efforts should also be made to combat piracy, perfect knowledge information screening system and knowledge pricing system, and avoid low-quality information. User evaluation mechanisms should be strictly carried out to regularly assess user satisfaction, and sufficient importance 
attached to user opinions and suggestions. KSPs are also suggested to highlight platform management and maintenance, protect the personal privacy of users, and formulate humanized after-sales service strategies, to ensure product quality and platform service quality. Furthermore, KSPs should be user-oriented, fully disclose the information that users care about, and keep a wary eye on information homogeneity (e.g., mutual imitation and plagiarism). Efforts should be made to effectively integrate and utilize fragmented information for knowledge processing, promote the comprehensive and systematic dissemination of knowledge, and ensure that the quality of knowledge provided matches its price. In the end, KSPs should continue to explore new business models and unceasingly expand market segments. Different pricing strategies should be made targeting at different income groups, to improve the learning experience of users at different levels and enhance user stickiness. Vertical (professional) segmentation over content is also recommended to improve the professionalism and authoritativeness of various KSPs and provides users with better resources. Such segmentation is expected to enable KSPs to satisfy diversified user groups, thereby leaving a satisfactory impression on users and facilitating the sustainable development of KSPs.

\subsection{Limitations}

Despite confirming that ECM and IS theories can be applied to the research on users' willingness for continuous use of KSPs, this study is beset by some limitations and deficiencies. First of all, although the respondents cover different groups from universities and enterprises, it is undeniable that random filling-in may exist. The online questionnaire designed in this study is mainly targeted at Chinese users, leading to that the findings may not be suitable for KSPs in other countries. Meanwhile, the questionnaires were distributed first among the author's friends and acquaintances and then spread to more people with the help of them, which may lead to certain similarities among the respondents enrolled in this survey in terms of age and education background and inadequate demographic differences. Therefore, future studies are suggested to expand respondents from different countries (e.g., the United States and Europe) to ensure the diversity of respondent sources. Moreover, this study fails to distinguish user behaviors under different knowledge payment models, including paid columns, voice services, online question-and-answer and more. Under the different models, there may be disparities in user needs and user habits, so future studies should conduct more detailed classification and comparative analysis. In conclusion, this study mainly integrates ECM and IS Success theories. As such, there are still many factors with research value that need to be further explored, such as TAM theory, trust, use habits, and theory of planned behavior, which are to be the emphases of subsequent studies.

Author Contributions: Conceptualization, S.P., P.B. and W.G.; Data curation, S.P., P.B.; Formal analysis, W.G.; Funding acquisition, S.P.; Investigation, P.B.; Methodology, S.P. and W.H.; Project administration, J.K.; Software, W.H.; Writing—original draft, J.K. and W.G.; Writing—review and editing, J.K. All authors have read and agreed to the published version of the manuscript.

Funding: This research received no external funding.

Conflicts of Interest: The authors declare no conflict of interest.

\section{Appendix A}

\begin{tabular}{clc}
\hline \multicolumn{1}{c}{ Variables } & \multicolumn{1}{c}{ Measurement Indexes } & Literature Sources \\
\hline & Use of the knowledge sharing platform can facilitate my & \\
& learning or working process. \\
Perceived Usefulness & $\begin{array}{l}\text { Use of the knowledge sharing platform can help me acquire my } \\
\text { desired information resources. }\end{array}$ & {$[49,51]$} \\
& Knowledge sharing platform is a learning style suitable for me. \\
& Knowledge sharing platform is on the whole useful to me. & \\
\hline
\end{tabular}




\begin{tabular}{|c|c|c|}
\hline Expectation Confirmation & $\begin{array}{l}\text { My user experience of the knowledge sharing platform is better } \\
\text { than expected. } \\
\text { Functions offered by the knowledge sharing platform are more } \\
\text { than expected. } \\
\text { Effects of using the knowledge sharing platform is better than } \\
\text { expected. } \\
\text { My expectations of the knowledge sharing platform are satisfied } \\
\text { after use. }\end{array}$ & {$[49,51]$} \\
\hline System Quality & $\begin{array}{l}\text { System response to the knowledge sharing platform is fast. } \\
\text { System performance of the knowledge sharing platform is } \\
\text { steady. } \\
\text { Operation of the knowledge sharing platform can achieve } \\
\text { expected outcomes. } \\
\text { It is convenient to operate the knowledge sharing platform. }\end{array}$ & {$[81,82]$} \\
\hline Information Quality & $\begin{array}{l}\text { Information output by the knowledge sharing platform } \\
\text { demonstrates high reliability. } \\
\text { Information output by the knowledge sharing platform has a } \\
\text { high content quality. } \\
\text { Information provided by the knowledge sharing platform is } \\
\text { all-dimensional. } \\
\text { Information provided by the knowledge sharing platform is } \\
\text { easy to understand. }\end{array}$ & {$[81,82]$} \\
\hline Service Quality & $\begin{array}{l}\text { Service quality of the knowledge sharing platform is beyond my } \\
\text { expectation. } \\
\text { The knowledge sharing platform provides excellent service } \\
\text { quality on the whole. } \\
\text { The knowledge sharing platform provides reliable service for } \\
\text { users. } \\
\text { The knowledge sharing platform can soon respond to my } \\
\text { request. }\end{array}$ & {$[77,78]$} \\
\hline Satisfaction & $\begin{array}{l}\text { Use of the knowledge sharing platform makes me happy. } \\
\text { My use of the knowledge sharing platform is almost barrier-free. } \\
\text { It is a wise choice made by me to use the knowledge sharing } \\
\text { platform. } \\
\text { Use of the knowledge sharing platform is satisfactory to me on } \\
\text { the whole. }\end{array}$ & [79] \\
\hline Continued Use Intention & $\begin{array}{l}\text { I will continue using the knowledge sharing platform in the } \\
\text { future. } \\
\text { I will maintain my knowledge sharing platform use frequency in } \\
\text { the future. } \\
\text { I tend to use the knowledge sharing platform rather than other } \\
\text { software in the future. } \\
\text { I will recommend the knowledge sharing platform to others. }\end{array}$ & {$[84,87]$} \\
\hline
\end{tabular}

\section{References}

1. Feng, E. Chinese Tech Apps Trade Knowledge for Cash. 2017. Available online: https://www.Ft.Com/ Content/Add21080-0ace-11e7-97d1-5e720a26771b\#Comments-Anchor (accessed on 20 November 2019).

2. Zhang, X.; Jiang, S.; Xiao, Y.; Cheng, Y. Global Challenges and Developmental Lessons in the Knowledge Sharing Economy. Taylor Fr. 2018, 21, 167-171. [CrossRef]

3. Yuan, L. Chinese willing to pay for trustworthy web content. Available online: https://www.wsj.com/articles/ chinese-show-willingness-to-pay-for-clicks-1483555104 (accessed on 4 January 2017).

4. Aldholay, A.; Isaac, O.; Abdullah, Z.; Alrajawy, I.; Nusari, M. The role of compatibility as a moderating variable in the information system success model: The context of online learning usage. Int. J. Manag. Hum. Sci. (IJMHS) 2018, 21, 9-15.

5. Guo, S.; Guo, X.; Fang, Y.; Vogel, D. How doctors gain social and economic returns in online health-Care communities: A professional capital perspective. J. Manag. Inf. Syst. 2017, 34, 487-519. [CrossRef] 
6. Wasko, M.L.; Faraj, S. Why should I share? Examining social capital and knowledge contribution in electronic networks of practice. MIS Q. 2005, 29, 35-57. [CrossRef]

7. National Information Center: China's Sharing Economy Development Annual Report 2019. Available online: http://www.sic.gov.cn/archiver/SIC/UpFile/Files/Default/20190301115908284438.pdf (accessed on 25 November 2019).

8. Zhang, J.; Zhang, J.L.; Zhang, M.Y. From free to paid: Customer expertise and customer satisfaction on knowledge payment platforms. Decis. Support Syst. 2019, 127, 113140. [CrossRef]

9. Iresearch. Influencing Factors of Online Knowledge Payment Behavior in China 2018. Available online: http://www.199it.com/archives/704931.html (accessed on 25 November 2019).

10. Penguin Intelligent. Knowledge Payment Economy Report: How many Chinese netizens are willing to spend money on buying experience? Available online: https://tech.qq.com/a/20160808/007138.htm (accessed on 30 November 2019).

11. Lai, H.M.; Chen, T.T. Knowledge sharing in interest online communities: A comparison of posters and lurkers. Comput. Hum. Behav. 2014, 35, 295-306. [CrossRef]

12. Guttentag, D.A. Disruptive innovation and the rise of an informal tourism accommodation sector. Curr. Issues Tour. 2015, 18, 1192-1217. [CrossRef]

13. Tussyadiah, I.P. Strategic self-Presentation in the sharing economy: Implications for host branding. In Information and Communication Technologies in Tourism; Springer: Cham, Switzerland, 2016; pp. 695-708.

14. Turban, E.; Outland, J.; King, D.; Lee, J.K.; Liang, T.P.; Turban, D.C. Innovative EC Systems: From E-Government to E-Learning, E-Health, Sharing Economy, and P2P Commerce. In Electronic Commerce; Springer: Cham, Switzerland, 2018; pp. 167-201.

15. Koo, D.M.; Choi, Y.Y. Knowledge search and people with high epistemic curiosity. Comput. Hum. Behav. 2010, 26, 12-22. [CrossRef]

16. Alsabawy, A.Y.; Cater-Steel, A.; Soar, J. Determinants of perceived usefulness of e-Learning systems. Comput. Hum. Behav. 2016, 64, 843-858. [CrossRef]

17. Jin, J.; Yan, X.; Li, Y.; Li, Y. How users adopt healthcare information: An empirical study of online q \& a community. Int. J. Med. Inf. 2015, 86, 91-103.

18. Joo, Y.J.; Joung, S.; Son, H.S. Structural relationships among effective factors on e-Learners' motivation for skill transfer. Comput. Hum. Behav. 2014, 32, 335-342. [CrossRef]

19. Mohammadi, H. Investigating users' perspectives on e-Learning: An integration of tam and is success model. Comput. Hum. Behav. 2015, 45, 359-374. [CrossRef]

20. Shen, X.L.; Cheung, C.M.K.; Lee, M.K.O. What leads students to adopt information from wikipedia? An empirical investigation into the role of trust and information usefulness. Br. J. Educ. Technol. 2013, 44, 502-517. [CrossRef]

21. Yan, B.; Jian, L. Beyond Reciprocity: The bystander effect of knowledge response in online knowledge communities. Comput. Hum. Behav. 2017, 76, 9-18. [CrossRef]

22. Usoro, A.; Sharratt, M.W.; Tsui, E. Trust as an antecedent to knowledge sharing in virtual communities of practice. Knowl. Manag. Res. Pract. 2007, 5, 199-212. [CrossRef]

23. Davenport, T.H.; Prusak, L. Working Knowledge: How Organizations Manage What They Know; Harvard Business Press: Boston, MA, USA, 1998.

24. Holthouse, D. Knowledge research issues. Calif. Manag. Rev. 1998, 43, 277-280. [CrossRef]

25. Musen, M.A. Dimensions of knowledge sharing and reuse. Comput. Biomed. Res. 1992, 25, 435-467. [CrossRef]

26. Cummings, J.N. Work groups, structural diversity, and knowledge sharing in a global organization. Manag. Sci. 2004, 50, 352-364. [CrossRef]

27. Dorsey, D.W. Hiring for knowledge-Based competition. In Managing Knowledge for Sustained Competitive Advantage: Designing Strategies for Effective Human Resource Management; Jossey-Bass: San Francisco, CA, USA, 2003.

28. Maizza, A.; Fait, M.; Scorrano, P.; Iazzi, A. How knowledge sharing culture can become a facilitator of the sustainable development in the agrifood sector. Sustainability 2019, 11, 952. [CrossRef]

29. Fait, M.; Scorrano, P.; Mastroleo, G.; Cillo, V.; Scuotto, V. A novel view on Knowledge Sharing in the Agri-Food sector. J. Knowl. Manag. 2019, 23, 953-974. [CrossRef] 
30. Qi, T.; Wang, T.; Ma, Y.; Zhou, X. Knowledge payment research: Status quo and key issues. Int. J. Crowd Sci. 2019, 3, 117-137. [CrossRef]

31. Hsiao, K.L.; Chen, C.C. Value-Based Adoption of E-Book Subscription Services: The Roles of Environmental Concerns and Reading Habits. Telemat. Inform. 2017, 34, 434-448. [CrossRef]

32. Anja, L.; Kanishka, M. Fee or Free: When Should Firms Charge for Online Content? Manag. Sci. 2017, 63, 1150-1165.

33. Shen, X.L.; Cheung, C.M.; Lee, M.K. What leads students to adopt information from Wikipedia? An empirical investigation into the role of trust and information usefulness. Br. J. Educ. Technol. 2013, 44, 502-517.

34. Jing, J. Analysis and Research on Operating Mode of Voice Platform Based on Knowledge Payment. Open J. Soc. Sci. 2019, 07, 397-404.

35. Cai, S.; Luo, Q.F.; Fu, X.; Ding, G. Paying for Knowledge: Why People Paying for Live Broadcasts in Online Knowledge Sharing Community? In Proceedings of the PACIS 2018, Yokohama, Japan, 26-30 June 2013; p. 286.

36. Wang, C.Z. Knowledge Payment's Singularity and Future. Internet Econ. 2017, 1, 68-73.

37. Zeng, Q.; Zhong, X.C. The Design of Individual Knowledge Sharing Platform Based on Blog for Online Information Literacy Education. Phys. Procedia 2012, 33, 1426-1432.

38. Liu, Y.F.; Jia, F.F. Study of Sharing Behavior of Users Based on SNS. Inf. Sci. 2017, 1, 42.

39. Zou, B.H.; Luo, H. Knowledge Payment: Knowledge Dissemination Mode Centered on Openness, Sharing and Payment. New Media Res. 2017, 3, 110-112.

40. Liu, C.C.; Tao, S.Y.; Chen, W.H.; Chen, S.Y.; Liu, B.J. The effects of creative commons approach on collaborative learning. Behav. Inf. Technol. 2013, 321,37-51. [CrossRef]

41. DeLone, W.H.; McLean, E.R. Information systems success: The quest for the dependent variable. Inf. Syst. Res. 1992, 6, 373-384. [CrossRef]

42. Chiu, C.M.; Hsu, M.H.; Wang, E.T. Understanding knowledge sharing in virtual communities: An integration of social capital and social cognitive theories. Decis. Support Syst. 2006, 42, 1872-1888. [CrossRef]

43. DeLone, W.H.; McLean, E.R. The DeLone and McLean model of information systems success: A ten-Year update. J. Manag. Inf. Syst. 2003, 19, 9-30.

44. Chen, C.W.D.; Cheng, C.Y.J. Understanding consumer intention in online shopping: A respecification and validation of the DeLone and McLean model. Behav. Inf. Technol. 2009, 28, 335-345. [CrossRef]

45. Gao, L.; Bai, X. An empirical study on continuance intention of mobile social networking services: Integrating the IS success model, network externalities and flow theory. Asia Pac. J. Mark. Logist. 2014, 26, 168-189. [CrossRef]

46. Olive, R.L. A Cognitive Model of the Antecedents and Conse-Quences of Satisfaction Decisions. J. Mark. Res. 1980, 17, 460-469. [CrossRef]

47. Bhattacherjee, A. Understanding information systems continuance: An expectation-Confirmation model. MIS Q. 2001, 25, 351-370. [CrossRef]

48. Zhao, Y.; Fan, J.Y. Influencing Factors of the Continued Use of Social Media among College Students: A Comparative Study via WeChat, Weibo and Renren Network Cases. J. Intell. 2016, 35, 188-195.

49. Lin, C.S.; Wu, S.; Tsai, R.J. Integrating perceived playfulness into expectation-Confirmation model for web portal context. Inf. Manag. 2005, 42, 683-693. [CrossRef]

50. Chen, C.F. Investigating structural relationships between service quality, perceived value, satisfaction, and behavioral intentions for air passengers: Evidence from Taiwan. Transp. Res. Part A. 2008, 42, $709-717$. [CrossRef]

51. Vatanasombut, B.; Igbaria, M.; Stylianou, A.C.; Rodgers, W. Information systems continuance intention of web-Based applications customers: The case of online banking. Inf. Manag. 2008, 48, 419-428. [CrossRef]

52. Lin, W.S. Perceived fit and satisfaction on web learning performance: IS continuance intention and task-Technology fit perspectives. Int. J. Hum.-Comput. Stud. 2012, 70, 498-507. [CrossRef]

53. Stone, R.W.; Eveleth-Baker, L. Students' expectation, confirmation, and continuance intention to use electronic textbooks. Comput. Hum. Behav. 2013, 29, 984-990. [CrossRef]

54. Oghuma, A.P.; Libaque-Saenz, C.F.; Wong, S.F.; Chang, Y.W. An expectation-Confirmation model of continuance intention to use mobile instant messaging. Telemat. Inform. 2016, 33, 34-47. [CrossRef]

55. Chang, J.H.; Wang, S.H. Different levels of destination expectation: The effects of online advertising and electronic word-Of-Mouth. Telemat. Inform. 2019, 36, 27-38. [CrossRef] 
56. Hsu, C.L.; Lin, J.C.C. What drives purchase intention for paid mobile apps?-An expectation confirmation model with perceived value. Electron. Commer. Res. Appl. 2015, 14, 46-57. [CrossRef]

57. Lee, M.C. Explaining and predicting users' continuance intention toward e-Learning: An extension of the expectation-Confirmation model. Comput. Educ. 2010, 54, 506-516. [CrossRef]

58. Chow, W.S.; Shi, S. Investigating students' satisfaction and continuance intention toward e-Learning: An Extension of the expectation-Confirmation model. Proc. Soc. Behav. Sci. 2014, 141, 1145-1149. [CrossRef]

59. Lee, Y.; Kwon, O. Intimacy, familiarity and continuance intention: An extended expectation-Confirmation model in web-Based services. Electron. Commer. Res. Appl. 2011, 10, 342-357. [CrossRef]

60. Mouakket, S. Factors influencing continuance intention to use social network sites: The Facebook case. Comput. Hum. Behav. 2015, 53, 102-110. [CrossRef]

61. Nascimento, B.; Oliveira, T.; Tam, C. Wearable technology: What explains continuance intention in smart watches? J. Retail. Consum. Serv. 2018, 43, 157-169. [CrossRef]

62. Limayem, M.; Hirt, S.; Cheung, C. How habit limits the predictive power of intention: The case of information systems continuance. MIS Q. 2007, 31, 705-737. [CrossRef]

63. Li, Q.; Yin, M. Mobile APP Users Continued Subscription Intention-A ECT and IS Case Study of Health APP. J. Dalian Univ. Technol. Soc. Sci. 2017, 1, 81-87.

64. Zhou, T.; Lu, Y.B.; Zhang, J.L. Research on the Critical Success Factors of Mobile Commerce Website. E-Commer. Inf. Manag. 2011, 23, 61-67.

65. Liu, L.C.; Sun, K. Extending ECM-ISC to Mobile Search Users Continuance Usage: A-Theoretical Model. Libr. Inf. Serv. 2011, 55, 134-137.

66. Li, Q.; Li, X.; Yin, M. Continuance Usage Intention Research of Mobile Group-buying-Compare and Integration between ECM and IS Success Model. J. Mod. Inf. 2018, 38, 53-61.

67. Narvadha, V.; Robin, N.; Yogesh, K.D. What determines success of an e-Government service? Validation of an integrative model of e-Filing continuance usage. Gov. Inf. Q. 2018, 3, 161-174.

68. Fang, Y.H.; Chiu, C.M.; Wang, E.T.G. Understanding Customers' Satisfaction and Repurchase Intentions: An Integration of IS Suc-Cess Model, Trust, and Justice. Internet Res. 2011, 21, 479-503. [CrossRef]

69. Hsu, M.H.; Chang, C.M.; Chu, K.K. Determinants of Repur-Chase Intention in Online Group-Buying: The Perspectives of De-Lone \& McLean IS Success Model and Trust. Comput. Hum. Behav. 2014, 36, 234-245. [CrossRef]

70. Wang, W.T.; Wang, Y.S.; Liu, E.R. The Stickiness Intention of Group-Buying Websites: The Integration of the Commitment-Trust Theory and E-Commerce Success Model. Inf. Manag. 2016, 53, 625-642. [CrossRef]

71. Schaupp, L.C.; Bélanger, F.; Fan, W. Examining the Success of Websites Beyond E-Commerce: An Extension of the IS Success Model. J. Comput. Inf. Syst. 2009, 49, 42-52.

72. Greenberg, J.A.; Axen, K.V.; Schnoll, R.; Boozer, C.N. Coffee, tea and diabetes: The role of weight loss and caffeine. Int. J. Obes. 2005, 29, 1121. [CrossRef] [PubMed]

73. DeLone, W.H.; McLean, E.R. Information systems success measurement. Found. Trends Inf. Syst. 2016, 2, 1-116. [CrossRef]

74. Montesdioca, G.P.Z.; Maçada, A.C.G. Measuring user satisfaction with information security practices. Comput. Secur. 2015, 48, 267-280. [CrossRef]

75. Koivumäki, T.; Ristola, A.; Kesti, M. The effects of information quality of mobile information services on user satisfaction and service acceptance-Empirical evidence from Finland. Behav. Inform. Technol. 2008, 27, 375-385. [CrossRef]

76. Poulova, P.; Simonova, I. E-Learning reflected in research studies in Czech Republic: Comparative analyses. Procedia-Soc. Behav. Sci. 2014, 116, 1298-1304. [CrossRef]

77. Roca, J.; Chiu, C.M.; Martinez, F.J. Understanding e-Learning continuance intention: An extension of the technology acceptance model. Int. J. Hum.-Comput. Stud. 2006, 64, 683-696. [CrossRef]

78. Tajuddin, R.; Baharudin, M.; Hoon, T.S. System quality and its influence on students' learning satisfaction in UiTM Shah Alam. Procedia Soc. Behav. Sci. 2013, 90, 677-685. [CrossRef]

79. Xu, D.; Huang, W.W.; Wang, H.; Heales, J. Enhancing e-Learning effectiveness using an intelligent agent-Supported personalized virtual learning environment: An empirical investigation. Inf. Manag. 2014, 51, 430-440. [CrossRef]

80. Petter, S.; McLean, E.R. A meta-Analytic assessment of the DeLone and McLean IS success model: An examination of IS success at the individual level. Inf. Manag. 2009, 46, 159-166. [CrossRef] 
81. Hassanzadeh, A.; Kanaani, F.; Elahi, S. A model for measuring e-Learning systems success in universities. Expert Syst. Appl. 2012, 39, 10959-10966. [CrossRef]

82. Kim, K.; Trimi, S.; Park, H.; Rhee, S. The impact of CMS quality on the outcomes of e-learning systems in higher education: An empirical study. Decis. Sci. J. Innov. Educ. 2012, 10, 575-587. [CrossRef]

83. Saba, T. Implications of e-Learning systems and self-Efficacy on students outcomes: A model approach. Hum.-Cent. Comput. Inf. Sci. 2013, 2, 2-11.

84. Wen, S.L.; Chun, H.W. Antecedences to continued intentions of adopting e-Learning system in blended learning instruction: A contingency framework based on models of information system success and task-Technology fit. Comput. Educ. 2012, 58, 88-89.

85. Wu, J.H.; Wang, Y.M. Measuring KMS success: A respectification of the DeLone and McLean's model. Inf. Manag. 2006, 43, 728-739. [CrossRef]

86. Ayanso, A.; Herath, T.C.; O'Brien, N. Understanding continuance intentions of physicians with electronic medical records (EMR): An expectancy-confirmation perspective. Decis. Support Syst. 2015, 77, 112-122. [CrossRef]

87. Zheng, Y.; Zhao, K.; Stylianou, A.C. The impacts of information quality and system quality on users' continuance intention in information-Exchange virtual communities: An empirical investigation. Decis. Support Syst. 2013, 56, 513-524. [CrossRef]

88. Robinson, J.P.; Shaver, P.R.; Wrightsman, L.S. Measures of Personality and Social Psychological Attitudes; Academic Press: San Diego, CA, USA, 1991.

89. Hair, J.F.; Black, W.C.; Babin, B.J.; Anderson, R.E. Multivariate Data Analysis: A Global Perspective, 7th ed.; Pearson Education International: Swannanoa, NC, USA, 2010.

90. Nunnally, J.C. Psychometric Theory; McGraw Hill: New York, NY, USA, 1978.

91. Fornell, C.; Larcker, D.F. Evaluating structural equation models with unobservable variables and measurement error. Mark. Res. 1981, 18, 39-47. [CrossRef]

92. Gefen, D.; Straub, D.W.; Boudreau, M.C. Structural equation modeling and regression: Guidelines for research practice. Commun. Assoc. Inf. Syst. 2000, 4, 7. [CrossRef]

93. Hu, L.T.; Bentler, P.M. Cutoff criteria for fit indexes in covariance structure analysis: Conventional criteria versus new alternatives. Struct. Equ. Model. 1999, 6, 1-55. [CrossRef]

94. Hair, J.F., Jr.; Hult, G.T.M.; Ringle, C.; Sarstedt, M. A Primer on Partial Least Squares Structural Equation Modeling (PLS-SEM); Sage: Thousand Oaks, CA, USA, 2016.

95. Ashraft, A.; Jaafar, N.I.; Sulaiman, A. The mediation effect of trusting beliefs on the relationship between expectation-Confirmation and satisfaction with the usage of online product recommendation. South East Asian J. Manag. 2016, 10, 75-94.

96. Bhattacherjee, A.; Perols, J.; Sanford, C. Information technology continuance: A theoretic extension and empirical test. Comput. Inf. Syst. 2008, 49, 17-26. [CrossRef]

97. Ambalov, I.A. A meta-Analysis of IT continuance: An evaluation of the expectation-Confirmation model. Telemat. Inform. 2018, 35, 1561-1571. [CrossRef]

(C) 2020 by the authors. Licensee MDPI, Basel, Switzerland. This article is an open access article distributed under the terms and conditions of the Creative Commons Attribution (CC BY) license (http://creativecommons.org/licenses/by/4.0/). 